\title{
Clausewitz a través de la mirada de Raymond Aron. Vigencia y proyecciones
}

\section{Clausewitz through the eyes of Raymond Aron. Validity and projections}

\author{
Hernán Cornut \\ Facultad del Ejército - Universidad de la Defensa Nacional, Argentina \\ hernancornut@gmail.com
}

\section{Resumen:}

Quienes sostienen que la teoría clausewitziana ha perdido su valor en el presente, probablemente se equivoquen tanto como aquellos que pretendan atribuirle un carácter dogmático e imperecedero. Mientras la tecnología ha transformado la vida, la economía y la forma de combatir en términos instrumentales e ingenieriles, una buena parte de las nociones de Clausewitz parecen guardar validez. Por su parte, Raymond Aron es uno de los autores prominentes en el estudio de la estrategia y la política preconizadas por el noble alemán, aunque dentro del contexto de la Guerra Fría de mediados del siglo XX, y con un pensamiento geopolítico eurocéntrico. La propuesta consiste en reexaminar a Clausewitz para comprobar la vigencia de sus opiniones, y determinar en qué medida impacta en la realidad presente. Así, este trabajo tendrá por objetivos el análisis de la condición política o filosófica de De la guerra, la consideración sobre la validez de la dialéctica entre moderación y violencia, la utilidad presente acerca de la disquisición entre teoría y doctrina aportada por Clausewitz, y dirimir sobre la pertinencia del concepto trinitario de la guerra en el conflicto de hoy, entre otros aspectos. Todo ello en clave de respuesta para el uso de la fuerza legítima en manos de los Estados a la hora de resolver sus controversias.

Palabras clave: Historia, Historia militar, Política, Polemología.

\section{ABSTRACT:}

Those who argue that the Clausewitzian theory has lost its value in the present, probably make mistake as well as those intending to give it a character that is dogmatic and evergreen. While technology has transformed life, the economy and the way to fight in instrumental and engineering terms, a good part of the notions of Clausewitz seem to save validity. For his part, Raymond Aron is one of the prominent authors in the study of the strategy and the policy advocated by the German noble, although within the context of the cold war of the mid-20th century, and with a Eurocentric geopolitical thought. The proposal consists of re-examine to Clausewitz to check the validity of their opinions, and determine to what extent impact on the present reality. Thus, this work will have by objectives analysis of the political or philosophical condition of war, the consideration on the validity of the dialectic between moderation and violence, the utility present about the discussion between theory and doctrine provided by Clausewitz, and settle on the relevance of the Trinitarian concept of war in the conflict today, among other aspects. All this in terms of response to the use of legitimate force in the hands of States to resolve their disputes.

KEYWORDS: History, Military History, Politics, Polemology.

\section{INTRODUCCIÓN}

La densidad del discurso clausewitziano conlleva tanta riqueza como dificultad interpretativa. Esto ocasiona no pocas distorsiones en el sentido de sus conceptos, a veces por prejuicios, otras por conveniencia y muchas, quizás la mayoría, por la incapacidad para leer y entender al gran texto de polemología que De la Guerra (Clausewitz, 1983 [1832]) propone. En este sentido, fue Raymond Aron quien, a través de dos obras señeras como Sobre Clausewitz (2009 [1987]) y Pensar la Guerra, Clausewitz(1987 [1976]), introdujo un punto de vista centrado en el liberalismo europeo del siglo XX, que permitió descifrar el tratado en clave política, tal como Clausewitz lo hubiera pretendido. Si bien los textos de Aron se sitúan en la lógica amigo-enemigo que entrañaba la disuasión nuclear como producto de la Guerra Fría, las ideas acerca del pensamiento 
clausewitziano merecen una nueva y actual lectura, en razón de su vigencia y de sus implicancias para el mundo de hoy.

El objeto de este trabajo es evaluar la pervivencia conceptual de las ideas de Aron sobre Clausewitz. Esto supone una dificultad que cabe precisar, ya que sujeto y objeto, medio y fin, causa y efecto tenderán a imbricarse, en tanto Aron y el tratado se irán conjugando al punto de establecerse una simbiosis virtuosa entre el investigador y la naturaleza de su estudio. Para ello, recurriremos al análisis de los textos citados, pero también nos permitiremos valorar y enjuiciar los dichos directos del prusiano, en la idea de alcanzar un resultado significativo y a la vez claro en torno de Clausewitz y su obra, de la mano de Aron.

\section{la mirada de Aron. Maquiavelo y Clausewitz}

En líneas generales, Raymond Aron se propuso comprender la guerra como fenómeno integral desde la óptica clausewitziana. Esto se concretó mediante un análisis, tan desprejuiciado como la realidad del siglo XX lo permitía, que tendió a establecer un diálogo histórico que interpelaba a Clausewitz en el contexto de su época. Es cierto que Aron no estuvo exento de las subjetividades propias de quien interpreta -en un momento y un lugar- los hechos del pasado asumiendo el rol de difusor dentro del principio del comentario (Foucault, 1996, p. 62). Estuvo, por lo tanto, supeditado a los avatares que el discurso estratégico implica para la figura del analista que comunica su punto de vista relativo en torno a De la Guerra (Cornut, 2009, p. 62), pero también es cierto que Aron, consciente de esta limitación, acudió a la lectura directa de dichos textos, evitando los interlocutores y comparando los originales con las elucidaciones de terceros, que en su mayoría no habían entendido o bien habían tergiversado adrede al autor alemán (Aron, 1987 [1976], p. 8).

De la guerra es una obra trazada desde la perspectiva de análisis y crítica de los hechos pasados, sin determinismos, pero con la historicidad necesaria para entender que, si bien ningún evento se repite en forma idéntica, la guerra y sus alcances presentan ciertas regularidades de ocurrencia pasibles de estudio y comprensión (Aron, 2009 [1987], p. 49).

Ya en lo instrumental, Aron advierte sobre la conveniencia de leer el tratado en forma integral; esto es, relacionando las expresiones y contrastando su significado, según en la parte del texto en que se encontraren. Debido a que Clausewitz admitió -en una nota presumiblemente escrita alrededor de 1830- lo inacabado de su obra, y la necesaria revisión que el cólera le impidió, el lector actual debe hacer un esfuerzo de síntesis y comparar en forma permanente los juicios contenidos, a fin de comprender lo que en una primera impresión aparece como contradictorio. La lectura comprensiva en estos términos aclara el conocimiento y permite ir al fondo de las cuestiones que se plantean (Aron, 1987 [1976], p. 4).

Una primera observación de Aron nos presenta la influencia de Maquiavelo sobre Clausewitz, algo que otros autores también abordaron con posterioridad (Fernández Vega, 1993, p. 75). La relación devendría de la lectura que el alemán habría hecho con detenimiento sobre El Príncipe (Maquiavelo, 1994 [1531]) y en menor medida sobre Del arte de la guerra (Maquiavelo, 2002 [1520]). Esto encuentra sentido en términos de lo que se denomina realpolitik, y se refleja en la concepción del poder político como rector de las estructuras militares, y que monopoliza la violencia legal a través del Estado mediante el recurso a la guerra (ad bellum). Sin duda hay en El Principe indicios claros de la subordinación de lo militar a lo político y, más aún, una expectación acerca de la guerra como principal responsabilidad de la política. Se presentan alusiones definidas en torno del vínculo entre las leyes y las armas, que trasunta la vigencia y respaldo del cumplimiento de la norma a la sombra del recurso fundado en la fuerza, lo que se fortalece en sentencias tales como: "El Príncipe no ha de tener otro objeto, ni abrigar otro propósito, ni cultivar otro arte, que el que enseña el orden y la disciplina de los ejércitos" (Maquiavelo, 1994 [1531], p. 93).

Pero una mirada más detallada nos propone una articulación entre las fórmulas que ambos textos dejaron como legado. Si para Maquiavelo el fin (político por definición) justifica los medios a ser empleados en sentido amplio, para Clausewitz la guerra (en tanto medio) es la continuación de la política (fin) a través del recurso 
de la violencia legal. Adviértase la pertinencia entre las sentencias y la íntima relación de sus contenidos. Es evidente la influencia del florentino sobre Clausewitz como también la elaboración que este último concibió sobre esos conceptos. Esta perspectiva mantiene actualidad en las relaciones de política y guerra.

\section{LA ESENCIA DEL DISCURSO CLAUSEWITZIANO}

Ahora bien, ¿̇sobre qué aspectos esenciales Raymond Aron proyecta su pensamiento esclarecedor? Sin duda que son varios y sobre ellos iremos desgranando ideas, opiniones y puntos de vista.

En principio, Aron aborda De la Guerra a través de una noción compuesta por dos términos antitéticos. Por un lado, el aniquilamiento con preponderancia y autonomía de lo militar, que induce a interpretar a Clausewitz desde una dimensión táctica, lineal y reduccionista y también militarista. Quienes interpreten el tratado en estos términos no encontrarán ninguna característica por fuera del combate y habrán procurado respuestas rápidas y definitorias, como las que un manual para el uso de un artefacto podría brindar. Esta percepción de la guerra desemboca en la escalada y el denominado ascenso a los extremos de la máxima violencia. Muy por el contrario, otra postura es la que entiende a la guerra como instrumento de la política, que la subordina y rige. Esto nos habla de un posicionamiento esencialmente gubernamental con implicancias estratégicas amplias, en que la conducción política de la nación introduce un factor de prudencia que evita el ascenso a los extremos y establece una limitación, de hecho, al conflicto bélico, en vistas de generar condiciones que permitan la negociación durante y después de la guerra (Aron, 2009 [1987], pp. 89 y 90 ).

No obstante, el error de interpretación que adhiere a la primera línea de pensamiento deviene de considerar a De la Guerra como un texto filosófico, antes que político. Así, el aniquilamiento se concibe como la destrucción física y total, una suerte de desaparición del enemigo, mediante el uso de la fuerza en un grado teórico y, por tanto, irreal. Esta postura fue la que impulsó a Liddell Hart (1960 [1941]) para sindicar a Clausewitz como el "Madhi de la sangre" (Fernández Vega, 1993, p. 113) responsable de las matanzas masivas de ambas guerras mundiales. Muy por el contrario, la comprensión del tratado en términos estrictamente políticos permite abordar el aniquilamiento como el quiebre de la voluntad de lucha del enemigo, incapacitarlo física y moralmente para sostener el conflicto, y así doblegarlo sin aplicar más violencia que la necesaria para tal fin (Schmitt, 2014 [1967]).

El discurso clausewitziano será finalmente interpretado según cómo se aborde la realidad del conflicto, si desde el aniquilamiento o desde la política (Aron, 2009 [1987], p. 89). Si el punto de partida para el análisis es la destrucción lineal y objetiva de las fuerzas armadas del enemigo sin mayores consideraciones acerca de los objetivos últimos de la guerra, estaremos frente a la hegemonía del factor militar en las decisiones de fondo de la contienda, y tenderemos a unificar la conducción operativa y la de gobierno en una sola entidad. En este caso, el aniquilamiento se convierte en un fin en sí mismo, que no se subordina a ninguna decisión por fuera de lo militar, y es probable que desate la máxima violencia descontrolada. En contraposición, si la base de análisis del tratado es la de supremacía de la política, y la comprensión de la guerra como continuación de ella, se introduce un preámbulo de prudencia que debería evitar la escalada a los extremos. En palabras de Aron, "de la tensión entre los dos principios resulta históricamente la disociación entre dos escuelas de pensamiento, cada una de ellas reivindicando alguno de estos principios" (Aron, 2009 [1987], p. 90). Está claro que ninguna de estas formas en singular condensa la teoría clausewitziana, sino que antes deben entenderse en términos complementarios, donde cada una de estas opciones se combina en grado variable según los escenarios de conflicto armado a enfrentar. Así, Aron presenta a Clausewitz como un precursor del equilibrio europeo, al proponer la inteligibilidad de su alegato en función de la estabilidad que suponía aceptar que las diferencias entre Estados podían recurrir a la beligerancia para su resolución, pero en un marco de racionalidad, al dominar la política el factor militar, y restringir el aniquilamiento a la coacción de la voluntad del enemigo. "La sociedad europea de Estados, tal como la pensaba Clausewitz, implicaba, pues, que los miembros de esa sociedad se reconocieran recíprocamente, que a veces se combatieran sin que por ello quisieran aniquilarse 
mutuamente" (Aron, 2009 [1987], p. 89). De ser así, tanto la idea del prusiano como la disquisición de Aron se sostienen hasta la actualidad.

Muchas veces la repetición irreflexiva de la fórmula (la guerra es la continuación de la política por otros medios) opacó la comprensión y relevancia del discurso. El aporte sustancial de De la Guerra, hasta nuestros días, estriba en la sensatez que la política introduce en un hecho per se irracional, instalando una lógica por la que "el fin parcial de una acción remite al fin ulterior de la campaña, y ésta a su vez al fin político de la guerra" (Aron, 2009 [1987], p. 48). Esto permite distinguir la función y el valor de los eventos operativos, al discernir que la victoria militar es un instrumento para alcanzar el éxito en la guerra y, a su vez, es un medio para lograr los objetivos de la política (p. 33). Esta lectura de la fórmula otorga pleno sentido a la concatenación de medios y fines, los cuales parten del combate previsto por la táctica, pasan por la consecución de los objetivos de la campaña, y acaban por obtener el objetivo político señalado por la conducción del Estado al momento de emprender el conflicto bélico. Lo que queda es un pensamiento teleológico que orienta el poder desde la estrategia y define la aplicación de fuerza en el plano táctico.

La actualidad continúa preguntándose acerca de este enfoque, habida cuenta de la lógica nuclear del siglo XX y la hibridación de las guerras en el siglo XXI. ¿Es sustentable el papel de la política como marco del conflicto ante la posibilidad del holocausto atómico o frente a la despersonalización de las amenazas? En principio, digamos que a lo largo de la historia militar los avances tecnológicos han provocado cambios de paradigma, los que impulsaron modificaciones en la forma combatir y la consecuente transformación de los sistemas de armas involucrados. No obstante, la consistencia que alcanzó el papel de la política como rector de la violencia legítima después del ocaso de las guerras dinásticas y ante la aparición de los Estados nacionales parece no haber declinado. Así, en circunstancias de la Guerra Fría la disuasión nuclear se erigió en finalidad estratégica reemplazando a la estrategia de la decisión, pero siempre en manos de la política. Al decir de Aron: "el predominio de la política sustituye la decisión por la amenaza disuasiva y se esfuerza por enseñar a los hombres el arte de no autodestruirse, sin por ello someterse al imperio de uno solo" (Aron, 1987 [1976], p. 169). No obstante, Hiroshima y Nagasaki confirmaron la posibilidad de ascenso a los extremos de la violencia y, por ello, la condición práctica de la disuasión y su finalidad más clara.

Clausewitz introdujo la noción de que la guerra tiene una gramática propia, pero no una lógica propia. Vale decir que el hecho de armas se conduce militarmente de acuerdo al arte de la guerra y la capacidad profesional de los generales, pero se supedita a la lógica que la política determina para su consecución. Así, la lógica es atributo de la política, mientras que la gramática pertenece a la estrategia. (Aron, 1987 [1976], p. 176). Por lo tanto, no existe la posibilidad de una autonomía de la guerra que desconozca la lógica política de su cometido, y que no corra el riesgo de ser incoherente.

La noción de la política como legisladora no implica más que la idea de que el instrumento debe someterse a las intenciones de quien lo utiliza. Éste no puede exigir al instrumento más de lo que da, ni emplearlo sin tener en cuenta su naturaleza propia (Aron, 1987 [1976], p. 235).

La claridad de estos conceptos es elocuente.

\section{LOS TIPOS DE GUERRA}

Aron (2009 [1987], p. 94) plantea tres tipologías de guerra posibles a partir de la teoría clausewitziana: la guerra convencional o clásica, la guerra nuclear, y una guerra de partisanos o insurgentes. La primera se identifica con el modelo real preconizado en su teoría; fue el tipo de conflicto que jalonó el siglo XX. Dos ejemplos claros son la guerra por las Islas Malvinas (1982) y la denominada segunda guerra del Golfo Pérsico (2003). Se distinguen por el enfrentamiento abierto de masas importantes de efectivos, la distinción ostensible entre combatientes y población civil, la existencia de Estados soberanos que dirimen sus diferencias mediante el ad bellum, y el respeto por las leyes y convenciones que regulan la guerra en términos de Derecho 
Internacional Humanitario y Derecho Internacional de los Conflictos Armados. Este modelo de conflicto quedó relativizado a partir del atentado a las Torres Gemelas (EEUU) en 2001.

La guerra nuclear fue la característica que distinguió el siglo XX, en el que la imposibilidad de la beligerancia atómica por riesgo del holocausto mediatizó las luchas hacia las periferias y dio lugar a la guerra revolucionaria. Para Aron, esta conflagración (atómica) se aproximaba al modelo teórico de guerra absoluta de Clausewitz, y, por ello, la hacía inviable en su concreción. En cuanto a la guerra de insurgencia, también correspondió a la realidad del siglo XX y se relacionaba con las luchas por las independencias tardías de las colonias africanas y asiáticas. Estas guerras nada tenían que ver con el fenómeno revolucionario que tocaremos más adelante, sino que remitía al concepto de pueblo en armas, cuyo mayor exponente había sido la resistencia española a la invasión napoleónica en el siglo XIX, y que tanto había impresionado al prusiano.

Quizás Aron no haya definido con precisión el modelo de guerra que ocupa las primeras décadas del siglo XXI, pero tampoco su lógica de conducción estaría por fuera del predominio de la política. Así, las llamadas guerras asimétricas en las que el terrorismo ha dejado de ser un instrumento o forma de violencia para transformarse en un actor estratégico han privado a los países centrales (principales víctimas del flagelo) de la iniciativa operacional. Esto generó la idea de guerra preventiva, por la cual se orienta al poder militar y se aplican los recursos tácticos de manera presuntiva, en un tiempo y un espacio sobre los que se carece de precisiones, pero que es necesario neutralizar ante la amenaza invisible. Pocas veces la guerra fue tan asimétrica como la que plantea el terrorismo actual, el cual ante la desventaja respecto del poder aplica sus métodos agresivos fuera de toda norma o convención y mimetiza a los combatientes con la población. No obstante, la política sigue prevaleciendo al determinar la oportunidad del conflicto, la condición preventiva del mismo y el tipo de guerra a emprender. Solo la política puede cumplir ese rol y responsabilizarse por las consecuencias de las acciones militares así definidas.

Un asunto ya esbozado y en directa relación con lo anterior es la dialéctica entre guerra real y guerra absoluta, que Clausewitz arguyó y Aron describe. A partir de ejemplificar el enfrentamiento bélico recurriendo a la figura de dos contrincantes singulares involucrados en un duelo, Clausewitz elaboró la noción de guerra en su sentido más amplio. Luego, para establecer las características de la guerra en su perspectiva real, tangible y posible, apeló a la noción de la guerra absoluta, la cual solo existe para Clausewitz en forma modélica y al solo efecto de constituir el marco de referencia que refuerce la idea de guerra real mediante la comparación entre lo posible y lo teórico. De esta manera, la guerra absoluta existe para contraponerse a la real, pero no porque pueda concretarse. La guerra absoluta no coincide con la real, porque el Estado no se reduce a la simplicidad del luchador aislado, ya que tiene un pasado y un futuro, porque debe tener en cuenta a su pueblo y servirse de la audacia y arte del comandante militar (Aron, 2009 [1987], p. 29). Cumple el rol de marcar el punto final de ascenso a los extremos de la violencia y se constituye en una medida preventiva en manos de la política, que advierte sobre los límites e implicancias para las voluntades enfrentadas. La guerra absoluta, entonces, desempeña una función teórica que se dirige a exponer la irracionalidad intrínseca de la conflagración, y una función praxiológica que recuerda a los adversarios el riesgo que conlleva la falta de prudencia en el marco de un hecho que carece de mesura y reflexión (Aron, 1987 [1976], p. 41). En ambos casos, las funciones caben estrictamente al ámbito de la política y mantienen vigencia en las beligerancias presentes.

El modelo teórico de guerra absoluta alimentó, mediante interpretaciones capciosas, el concepto de guerra total. Esta noción pergeñada por Erich Ludendorff (1964 [1935]) luego de su participación en la Gran Guerra -y sostenido por Hitler a comienzos de la Segunda Guerra Mundial- propone un tipo de conflicto dominado por la hostilidad sin restricciones. Pero el detalle saliente es que, al redoblar la apuesta de violencia de la guerra absoluta, intenta salir de la teoría y plantear el tema racial o comunidad étnica como sujeto histórico del enfrentamiento bélico, y a sus enemigos como los adversarios transhistóricos del pueblo alemán (Aron, 1987 [1976], p. 163). Esto nos permite elaborar algunas ideas más allá de los textos analizados. Pareciera que la guerra total habilita la violencia extrema porque persigue un fin de supremacía por fuera de las condiciones 
de la guerra real. Esto significa que, lejos de procurar la paz y el restablecimiento de las condiciones anteriores al inicio de la guerra, lo que busca es la destrucción del enemigo en tanto etnia particular, y la única forma de lograrlo es mediante el aniquilamiento físico que implica la desaparición del adversario antes que la coacción sobre su voluntad de lucha. De este modo, al modelo teórico de guerra total solo le puede caber como instrumento de acción el aniquilamiento físico, tan acabado y teórico como el fin procurado. De aquí se puede deducir que, si bien la guerra total permanece en un plano prototípico, alcanza comprensión analítica cuando se la examina desde la perspectiva del odio -en este caso racial-, que impulsa los instintos más básicos del ser humano. El reemplazo de un fin de características estatales - como objetivo de la guerra- por otro de propiedades étnicas opaca la cualidad de la prudencia en manos de la política y al mismo tiempo exacerba las atrocidades.

Lo anterior permite entender por qué las cuestiones sociales, religiosas y culturales tiñen de fanatismo la acción de guerra y desconocen los límites de cualquier norma o convención, ya que se reemplaza al objetivo de la guerra clásica (la cual acepta leyes positivas y pautas para su desarrollo) por el de la procura de la desaparición de un enemigo permanente, la cual será altamente improbable. Así las cosas, Aron no vivió esta realidad planetaria de terrorismo y por lo tanto no tipificó este tipo de conflicto que nosotros advertimos como una derivación de la guerra absoluta, pero en este caso con cierta aptitud de ocurrencia práctica. De ser así, estaríamos asistiendo a una suerte de regresión a la barbarie, en la que los Estados nacionales no encuentran posibilidad de aplicación eficiente de sus recursos militares para combatir a un enemigo que, dentro del concepto de asimetría, no respeta ninguna ley más que la de su propia supervivencia. Si volviésemos a la figura del duelo propuesta por Clausewitz, entenderíamos que la guerra total así planteada se asemeja a la oposición singular de dos contrincantes en los cuales prima el odio como propulsor de la sobrevivencia y, al mismo tiempo, se diluye el discernimiento que la política debería aportar, ya que están en juego pasiones mucho más sensibles que los fines soberanos o intereses vitales de un Estado.

\section{ClauseWitz Y LA guerRa ReVolucionaria}

Uno de los puntos más sensibles del tratado, según Aron, es la interpretación e interés que De la Guerra tuvo para la ideología marxista o, mejor dicho, para la denominada guerra popular (Aron, 2009 [1987], p. 39). En principio, Clausewitz identificó el protagonismo y la potencia que el pueblo posee en torno de la guerra como hecho social y político. Luego, definió su rol para la defensa del territorio, de la patria y de sus propios intereses. De allí el concepto de pueblo en armas, o sea del ciudadano que empuña las armas y se hace cargo de legitimar el bien común a través de las mismas y, lo que es muy importante, contra el invasor extranjero. Aquí aparece una primera condición que acompaña la idea clausewitziana y que después será manipulada por los ideólogos de izquierda: las guerras de insurgencia tienen que ver con los procesos de descolonización del siglo XX, con los partisanos que se autoorganizan para repeler al ejército alemán en Francia o en los Balcanes y evoca la visión que el prusiano tuvo por la reacción de los españoles ante Napoleón. Esto conduce a una especie de guerra popular, que se determina por los sujetos de la acción -vale decir, los ciudadanos, que encarnan una acción de resistencia mediante la defensa de lo suyo (Aron, 1987 [1976], p. 74)-, y que poco o nada tiene que ver con la llamada guerra revolucionaria del siglo XX. Será Carl Schmitt quien establezca la diferencia entre el guerrillero telúrico o romántico y el revolucionario profesional, lo que equivale a decir, entre las luchas de liberación nacional de coloniajes y las guerras revolucionarias que procuraron exportar un modelo ideológico (Aron, 1987 [1976], p. 164). Esto nos coloca frente a una noción central, a saber, que se debe partir de la finalidad política de la guerra para describir el tipo de lucha y el combatiente. Sin ambages, el pueblo en armas de Clausewitz nada tenía que ver con los movimientos armados comunistas de mediados del siglo XX, no obstante, esto no impidió que se lo calificase como un teórico de la guerrilla y la insurrección popular marxista (Aron, 1987 [1976], p. 18). Pero tampoco se debe confundir al pueblo en armas con la nación en armas, término este último que Clausewitz no tiene en cuenta, precisamente por ser 
una concepción posterior, de fines del siglo XIX, cuyo mentor fue Colmar von der Goltz (1927 [1883]). Es de notar que tampoco Raymond Aron se detiene sobre este concepto, lo que llama la atención si se tiene en cuenta lo profuso y profundo de sus cavilaciones en torno de Clausewitz.

Ya en el terreno de la apropiación ideológica comunista de De la Guerra, diremos que su repercusión fue inmensa, tanto como para que Stalin condujera a Rusia durante la Segunda Guerra Mundial de acuerdo a los principios del tratado, y Mao Tse Tung elaborase la doctrina del conflicto prolongado o estrategia sin tiempo a partir de la experiencia española entre 1808 y 1811 (Aron, 1987 [1976], p. 43). Quizás la mayor apropiación del comunismo, y el maoísmo en particular, haya sido la combinación -en el plano tácticode una concepción general expectante con acciones ofensivas permanentes de hostigamiento. Y aquí radica otra importante diferencia entre las actitudes operacionales de la nación en armas y las del pueblo en armas: mientras el primero concibe la situación estratégica en términos defensivos (de su territorio y su patrimonio), el segundo endereza su acción ofensivamente, alineando política, estrategia y táctica en idéntico sentido. De ello resulta que las guerras revolucionarias son eminentemente violentas y, como ya se dijo, tienden a ascender a los extremos fácilmente.

En esencia los discípulos marxistas de Clausewitz insertan el pensamiento estratégico de éste en una filosofía de la historia cuya culminación estará signada por la victoria total del proletariado sobre el resto de las clases sociales y, por ende, la eliminación de las guerras (Aron, 1987 [1976], p. 193). Esta supresión de las guerras se vincula con la noción de que "los conflictos continúan o expresan los regímenes internos de los Estados enfrentados” (Aron, 1987 [1976], p. 77). Así, para el maoísmo y el marxismo-leninismo, solo la desaparición del capitalismo llevará a un gran conglomerado socialista-comunista internacional, en un mundo que finalmente alcanzará la paz perpetua. Para Lenin la única guerra justa es la del proletariado contra el capital (Aron, 1987 [1976], p. 163). De esta manera, para el marxismo no existe la posibilidad de una guerra entre Estados, ya que la sociedad no apoyaría ningún esfuerzo bélico ante la falta de cohesión e intereses compartidos entre clases que son, ante todo, enemigas (Aron, 1987 [1976], p. 173).

Aron (1987 [1976], p. 155) también señala en forma precisa las contradicciones del castrismo cubano y la teoría del foquismo, ya que constituyen interpretaciones falsas de la teoría clausewitziana, devenida en guerra revolucionaria, según la cual, si la guerrilla alienta y genera la insurrección, "permitiría no esperar a que las condiciones sociopolíticas para una revolución hayan madurado" (p. 155), y así imponer de hecho y violentamente el cambio de situación política. El autor observa que esto derivó al menos en tres aspectos controversiales: que el pueblo puede vencer a un ejército regular (lo cual es altamente improbable); que en América Latina el teatro de operaciones revolucionario es rural (lo cual es opinable y solo se da en determinadas circunstancias), y que el foco de rebelión acelerará la insurrección (lo cual casi siempre es falso) (p. 155). Todo lo anterior acompañó el desarrollo de la realidad y acabó por implosionar en 1989 con la caída del Muro de Berlín y el fin del comunismo. La situación mundial y regional actual valida los dichos de Aron y otorgan vigencia a sus observaciones. También está en vigor el concepto acerca de que el marxismoleninismo, si alcanza el poder, olvida sus principios básicos y reconstruye rápidamente la identidad nacional, el mito de origen y la figura del Estado (Aron, 1987 [1976], p. 173). Por último, y para desmitificar el carácter de los conflictos revolucionarios, coincidimos con Aron en que la guerra se define como tal por el empleo predominante de las fuerzas armadas, de manera que la lucha de clases entre sí no puede ser encuadrada como hecho bélico, en tanto no participen las tropas regulares a disposición del Estado (Aron, 1987 [1976], p. 207).

\section{LA EXTRAÑA TRINIDAD}

Sin lugar a dudas uno de los aportes sustanciales de Clausewitz es el denominado concepto trinitario de la guerra. Sobre el final sorpresivo de su vida consideraba la necesidad de una profunda revisión y ordenamiento del tratado. En esa tarea se encontraba cuando murió el 16 de noviembre de 1831. No obstante, él mismo decía en una nota de 1830 que "El primer capítulo del Libro I es el único que considero acabado" (Clausewitz, 
1999 [1832], p. 175). Es precisamente en el final del capítulo 1 de ese Libro donde encontramos la cuestión 28 bajo el título "Conclusión para la Teoría”, y allí se define una característica central de la guerra:

La guerra, por lo tanto, no es solamente un verdadero camaleón, por el hecho de que en cada caso concreto cambia en algo su carácter, sino que es también una extraña trinidad, si se la considera como un todo, en relación con las tendencias que predominan en ella. Esta trinidad la constituyen el odio, la enemistad y la violencia primitiva de su esencia (...) el juego del azar y las probabilidades (...) y el carácter subordinado de instrumento político (...) (Clausewitz, 1983 [1832], pp. 25 y 26).

En rigor, la noción trinitaria introduce la necesidad de mantener en equilibrio y controlados los aspectos irracionales dimanados de las pasiones que instigan la lucha y que se encuentran presentes en el pueblo, armonizados con el talento militar que conduzca las operaciones tácticas y estratégicas con idoneidad profesional para minimizar los efectos del azar, y, a su vez, todo ello contenido en el gran diseño que la política haya previsto para la contienda, bajo la forma de objetivos y fines. Así, la tríada se traduce en pueblo, ejército y gobierno.

En palabras de Aron, es dable entender al concepto trinitario como una especulación acerca de la propia historicidad de la guerra a través de los tiempos, ya que los tres componentes han integrado todos los conflictos armados, si bien en grado variable en cuanto al peso y preeminencia de cada uno (Aron, 2009 [1987], p. 31). No hay dudas de que la definición trinitaria de la guerra fue un salto conceptual muy importante para la teoría bélica, como consecuencia de la conformación de los Estados nación, luego de la paz de Westfalia en 1648 (Aron, 1987 [1976], p. 91). Ahora bien, el asunto es determinar si la idea mantiene validez en el tercer milenio. Es cierto que ha tenido detractores como Martin van Creveld (2007), quien en su libro La transformación de la guerra cuestiona la vigencia de esa idea. En líneas generales este autor disiente acerca de la vigencia de la "extraña" trinidad, estructurando su tesis en torno de dos aspectos. Por un lado, se concentra en el pueblo como lo disfuncional para mantenerse en uso la idea trinitaria, por lo que arguye la incapacidad de las guerras actuales para establecer diferencias claras entre el combatiente y el ciudadano civil, algo que las guerras posdinásticas se habían preocupado por enfatizar, aunque no siempre con pleno éxito. Está fuera de discusión lo inorgánico de las fuerzas que toman las armas bajo la condición terrorista de los conflictos armados de hoy, pero es justamente en el hecho de entender al pueblo -dentro de la tríada- a partir de la simple característica de su incorporación masiva al servicio militar (van Creveld, 2007, pp. 66 y ss.), lo que explica su disenso con Clausewitz. En efecto, el prusiano se refería al pueblo como génesis de la legitimación de la guerra a emprender por la política, y dueño de las pasiones que justifican la defensa de sus intereses vitales en el marco del Estado nación. Este concepto de pueblo (clausewitziano) se posiciona como el aval necesario de la política para escalar una crisis hasta llegar al sacrificio de la guerra. Vale decir, que el pueblo así entendido se constituye en legitimador de las acciones militares, abarcando una gama amplia de cuestiones que van desde la opinión pública hasta la aceptación del esfuerzo bélico de un país en lo humano y lo económico. El pueblo, visto así, es mucho más que su rol de combatiente individual.

El otro punto importante que genera disenso en van Creveld es la figura del Estado como protagonista de la guerra. "La violencia organizada solo puede ser denominada guerra si es librada por el Estado, para el Estado y contra otro Estado" (van Creveld, 2007, p. 63). Convenimos con el autor acerca de las dos primeras consideraciones, pero no así con la última. Una de las características que venimos tratando de las guerras del siglo XXI es la asimetría y la hibridación de las fuerzas, que se militarizan para cambiar la situación política y estratégica, sin llegar a conformar tropas totalmente regulares, lo que transforma al terrorismo en un actor estratégico. Esta mutación del conflicto genera un replanteo de la autoridad del Estado, que procura de sus fines bajo la irreemplazable función de la política, y en contra de quienes se opusieren a dicha acción, muy por encima de las características del enemigo del que se tratare. Si los intereses vitales se encuentran en jaque y la política decide el pleno uso de la fuerza legal, no deberían existir pruritos acerca de su empleo. Es cierto que esto obliga a una observación puntillosa de los aspectos normativos del empleo militar en contra de un enemigo de este tipo, pero no es menos cierto que la virulencia de la amenaza en oposición induce al restablecimiento de la paz, mediante la aplicación de todas las herramientas a disposición del Estado. De 
hecho, bajo el título de Nuevos Enfoques de la Seguridad Hemisférica, el gobierno argentino dirigió una respuesta al cuestionario planteado por la Organización de los Estados Americanos en diciembre de 2001, en la que daba cuenta -junto a la casi totalidad de los países sudamericanos- de una clara percepción acerca de cómo había mutado el conflicto a partir del atentado a las Torres Gemelas, y advertía sobre la necesidad de enfrentar dichos desafíos en forma integral (a nivel regional) e interagencial dentro de cada país. Fue la propia evolución de las formas del conflicto lo que modificó la perspectiva de que las Fuerzas Armadas solo deben enfrentar enemigos de carácter estatal, para habilitarlas al uso pleno de la fuerza en el caso que el poder político lo considerare ineludible. Paradójicamente, van Creveld nos habla de la transformación de la guerra y sus actores estratégicos, pero no aporta soluciones, más allá de criticar a la teoría clausewitziana por su anacronismo. Todo el razonamiento anterior nos permite colegir acerca de la vigencia del concepto trinitario $y$, por ende, la persistencia del discurso de Raymond Aron en el presente que nos toca vivir.

\section{TEORÍA VERSUS DOCTRINA}

Un tema central en la obra de Clausewitz, y que Aron aborda en profundidad, es la visualización de $D e$ la Guerra como un verdadero corpus teórico antes que como una doctrina prescriptiva de la conducción militar de un conflicto armado. Coincidimos con Aron en que el prusiano pretendió elaborar una teoría que permitiera entender la naturaleza de la guerra y que no se confundiera con una doctrina, es decir, que enseñara al estratega militar a comprender su tarea sin alimentar la ridícula intención de comunicar el secreto de la victoria (Aron, 1987 [1976], p. 5). Ello por sí solo constituía una auténtica revolución en lo que hoy llamaríamos asuntos militares (p. 8). Pero, ¿cuál es el valor y cómo se define esta teoría de la guerra?:

Una teoría no precisa, para merecer este nombre, dar instrucciones a los actores. Toda actividad que usa los mismos medios en vista de los mismos fines da lugar a un estudio racional. Estudio analítico del objeto, en su organización natural, [que] conduce a un conocimiento elaborado, a discriminaciones claras; aplicada a la experiencia, y por lo tanto a la historia, crea una verdadera familiaridad con su objeto (Aron, 1987, p. 219).

Lo anterior encuentra pleno sentido en los dichos del propio Clausewitz:

Tendrá [la teoría] que educar la mente del futuro jefe en la guerra o, por lo menos, guiarlo en su autoeducación, pero no acompañarlo al campo de batalla. Del mismo modo [que] un tutor inteligente guía y ayuda el desarrollo intelectual del joven, sin que por ello lo tenga en andadores para el resto de su vida (Clausewitz, 1983 [1832], p. 82).

Entonces, la validez, pero también la vigencia de este enfoque en términos de teoría están dados porque la conducción de la guerra no admite la elaboración de una enseñanza positiva por tres razones: la acción recíproca de las fuerzas que se influyen aleatoriamente; la influencia e indeterminación de las magnitudes morales, y la singularidad y complejidad de cada situación en la cual toma sus decisiones el actor (Aron, 1987 [1976], p. 220). De esto se desprende la imposibilidad de mensurar o regular la guerra mediante leyes inmutables que ordenen y predigan los acontecimientos, o bien a través de rudimentos geométricos que se desentiendan de las dimensiones subjetivas de los hechos reales, como lo había intentado Jomini. Así, Clausewitz agrega valor al conocimiento y práctica de la guerra y logra tanto superar el estadio conceptual de su tiempo como mantener su validez hasta el presente.

Lo arriba expresado se condice lógicamente con las disquisiciones acerca de la guerra en términos de ciencia o arte. Si aceptamos que la guerra no obedece a leyes científicas y, por lo tanto, no puede ser condensada en un manual de prácticas predecibles y objetivas, entonces deberemos admitir que la guerra es esencialmente un arte, en la cual el talento del conductor puede ser optimizado mediante una teoría laxa que interprete la práctica con el auxilio de la experiencia obtenida de los hechos pasados. Este punto de vista modificó, en forma sustancial, la dirección de la guerra y se mantiene incólume hasta hoy por la contundencia de su fundamento. Tal como Aron lo manifiesta, la ciencia busca el conocimiento y el arte la creación o producción (Aron, 1987 [1976], p. 221). 


\section{Política, estrategia y táctica}

La perspectiva de los niveles de conducción de la guerra es un asunto que alimenta controversias, pero también aciertos. En efecto, tanto Clausewitz como Aron se expresan en función de la táctica, la estrategia y la política. Estos niveles por sí son correctos y claros en el plano teórico, aunque no tanto en la práctica. Los aciertos en la propuesta clausewitziana están dados por la noción de que la victoria militar es un medio para alcanzar el éxito en la guerra, y, a su vez, la guerra en un medio para lograr los fines de la política. Esto vincula al éxito de los combates o a la victoria con el plano táctico, y a la consecución de los fines políticos con la estrategia como herramienta a tal fin (Aron, 2009 [1987], p. 33). Así las cosas, la táctica se sirve de los combates y la estrategia de la batalla para resolver los objetivos de una campaña militar, los cuales, por su parte, deberán estar alineados con los fines de la política o, dicho de otro modo, con los objetivos que la política se propuso alcanzar a través de la guerra. De esta manera, Clausewitz propone y Aron decodifica que la política marca los fines, la táctica representa el nivel en el cual se aplican los medios en forma directa dentro de un razonamiento etiológico de causa-efecto, mientras que la estrategia se sirve de medios (el éxito de los combates tácticos) para obtener los objetivos militares que se condigan con los fines de la política para la guerra que se trate. Así, la estrategia discurre en un marco teleológico que vincula racionalmente medios y fines. No obstante, surgen algunos disensos entre la idea clausewitziana interpretada por Aron y la realidad del siglo XXI. En primer lugar, las diferencias entre política, estrategia y táctica son eminentemente teóricas, ya que en la praxis tienden a diluirse los límites y confundirse los campos de acción. Esto es natural y se acepta como tal al momento de llevar adelante las tareas y procesos que demanda la dirección de una guerra a nivel del Estado. En segunda instancia, Aron entiende a la estrategia ligada unívocamente a lo militar (Aron, 2009 [1987], pp. 128 y 129), cuando en la actualidad este concepto es discutido y reemplazado por una visión más amplia, en la cual la estrategia involucra todas las áreas y factores de poder del Estado nación. Quizás la influencia anglosajona, que tiende a amalgamar la estrategia con el accionar del instrumento militar y simplificar en forma arbitraria la realidad, haya influido sobre Aron en este sentido.

Sin embargo, el autor francés supo advertir el vacío del discurso clausewitziano en torno de la crisis (Aron, 1987 [1976], p. 195). La ausencia del concepto de crisis en el tratado descoloca el razonamiento contemporáneo, ya que una comprensión binaria de los conflictos actuales en el contexto taxativo de paz o guerra está alejada de la realidad planetaria, donde la incertidumbre es la circunstancia permanente en las relaciones entre Estados con intereses contrapuestos.

Un punto de destaque para la teoría de la guerra fue la consideración, dentro del tratado, de variables subjetivas como azar, fricción, genio militar y fuerzas morales. Todas ellas son reivindicadas por Aron (2009 [1987], p. 61) y guardan particular utilidad hasta nuestros días. La introducción de estos conceptos revolucionó el arte de la guerra, al proponer que cuestiones tan humanas como las descriptas formaban parte inescindible de las operaciones militares, sobre todo en su ejecución operativa y táctica. El azar, en particular, reviste especial relevancia en la toma de decisiones y éstas "siempre exigirán la participación de la afectividad” (Aron, 2009 [1987], p. 61). De alguna manera, Clausewitz vislumbra lo que un siglo y medio después será conocido como pensamiento complejo (Morin, 2001), que sintetiza la incapacidad del método cartesiano tradicional para comprender la realidad y generar efectos concretos. Aun cuando Clausewitz fue un hombre de su tiempo, sujeto al influjo del paradigma científico de la física mecánica (acción y reacción, tensión y reposo, punto culminante, centro de gravedad y fricción por mencionar algunos de los conceptos contenidos en el tratado), consiguió superar la transición entre el racionalismo del siglo de Las Luces y el romanticismo de la primera mitad del siglo XIX, y supo dimensionar en su justa medida el valor de lo subjetivo y humano en la guerra (Aron, 2009 [1987], p. 49). 


\section{LA DIALÉCTICA}

La influencia de Kant y Hegel sobre Clausewitz y su obra continúa siendo tema de debate. Raymond Aron admite tanto la existencia de los juicios críticos como de la dialéctica en los contenidos de De la Guerra, aun cuando manifiesta que el prusiano estudió a Kant en "dosis homeopáticas" (Aron, 1987 [1976], p. 281) y que no se puede precisar su conocimiento sobre Hegel. No obstante, y en el caso del empleo de la dialéctica, Aron, a instancias de Clausewitz, recurre a la relación entre opuestos para esclarecer el pensamiento de éste, y lo hace mediante binomios antitéticos, de los que tomaremos dos: lo moral y lo físico, y defensa y ataque.

En cuanto a lo moral y lo físico, el general alemán dio forma a esta antítesis mediante la representación, ya mencionada, del duelo proyectado a la lucha a escala entre voluntades. Así, partiendo de lo físico en la singularidad de dos luchadores enfrentados, plasma la contradicción al nivel de Estados -o bien actores estratégicos de magnitud, en la actualidad- que se enfrentan conscientemente para dirimir el conflicto en forma violenta. Para inducir a los conductores políticos y militares a no pasar por alto las magnitudes morales, se remontó a la propia naturaleza del fenómeno bélico en cuanto hecho social que compromete por igual al pueblo, al ejército y al gobierno (concepto trinitario de la guerra). Llama la atención sobre la indeterminación de la voluntad, en cuanto fuerza moral, pues nunca se sabe hasta qué extremos está resuelto a llegar el otro (Girard, 2010). Esto da lugar a una característica de la guerra: la incertidumbre sobre la relación de fuerzas y el desconocimiento de las intenciones del enemigo. Es preciso el coraje moral del conductor militar para decidir ante el peligro, no ya de su propia vida, sino de la supervivencia de los ejércitos que comanda y el logro o el fracaso de los fines políticos que le fueron confiados bajo la forma de objetivos militares de la guerra.

Clausewitz no acepta que el más débil tiene que ceder y avenirse a la ley del más fuerte. Por el contrario, la estrategia tiene por misión servir al débil, y esto consiste en asegurar la superioridad temporal del número en un lugar y un momento determinados. Suele enfatizar el número como factor de éxito, aun cuando en la noción de superioridad introduce un elemento moral, ya que la misma tropa, imbuida de virtud guerrera multiplica su poder de combate. El jefe y una tropa dotada de elevada moral de combate pueden compensar la inferioridad cuantitativa, aunque solo dentro de ciertos límites.

El jefe del ejército, dado que él anima y conduce al conjunto, debe conocer las diversas armas, la eficacia de cada una de ellas, la forma de combinarlas, la utilización de las plazas fuertes, sin por ello abrumarse con detalles. Del saber necesario para el virtuosismo se deduce el tipo de inteligencia que responde a las exigencias del arte de la guerra: resultan electos los cerebros críticos antes que los creadores, los que abarcan el conjunto antes que los que contemplan una sola dirección, las cabezas frías antes que las ardientes. En la guerra la inteligencia debe sobreponerse al peligro, los esfuerzos físicos, la incertidumbre y el azar. El coraje es la primera exigencia y virtud original, pero el coraje reviste dos formas: el de arriesgar la propia vida (físico) y el de asumir responsabilidades (moral). Según el método dialéctico, la primera clase de coraje es más concreta; la segunda lleva más lejos. Aquélla alimenta la constancia o la firmeza, ésta la audacia. La unión de ambas crea la especie más perfecta. Pero si una forma debe prevalecer en el jefe militar es la dimensión moral. No basta que los hombres adopten resoluciones con facilidad para merecer el calificativo de resueltos; es preciso que sus decisiones se sometan a la reflexión y prevalezcan sobre la duda. La resolución es el entendimiento que, con plena consciencia de las razones para dudar, ha reconocido la necesidad de decidir y las consecuencias fatales de la vacilación. Así, la resolución deriva más de los cerebros sólidos que de mentes brillantes.

En cuanto al binomio defensa-ataque, Clausewitz propone por un lado la idea de reciprocidad y por otro la noción de asimetría, en razón de la superioridad de la defensa. Utiliza el concepto de intención negativa ligado a la defensa para designar un combate que no persigue otro fin que impedir al enemigo alcanzar el suyo. ¿Cómo definir la defensa? Si la definimos por el fin, ésta consiste en conservar y su rasgo específico es la espera, pero no cualquier clase de espera. Una espera pasiva que no contemplase acciones para hacer fracasar el ataque dejaría de pertenecer a la guerra. La defensa rechaza al atacante o lo resiste. El tratado no emplea los términos rechazar y resistir en forma indistinta. El primero es el más general, el único pertinente; designa el acto que 
se opone efectivamente al ataque, el que provoca su fracaso. Rechazar un asalto -parar un golpe- permite alcanzar el fin de la defensa, esto es, guardar o conservar. Clausewitz utiliza tres nociones para describir la actitud defensiva: rechazar, esperar y conservar. El primero es el concepto, el segundo es la característica y el tercero es el fin. De las enunciaciones previas se deducen dos consecuencias aparentemente divergentes, pero que en realidad son compatibles e incluso complementarias:

No puede concebirse la defensa sin un golpe de vuelta; que este golpe de vuelta es un constituyente necesario de la defensa, mientras que en el ataque, el golpe o acción de atacar es en sí mismo una concepción completa. La defensa en sí misma no es necesariamente parte del ataque; pero el tiempo y el espacio, a los cuales está ligada, introducen la defensa dentro del mismo como un mal necesario (Clausewitz, 1983 [1832], p. 488).

La defensa es doblemente compleja. La espera forma parte de la maniobra defensiva, porque el atacante tiene la iniciativa y el defensor no para los golpes sino en el momento en que los recibe. La defensa necesita del ataque para convertirse en un concepto completo en función de la naturaleza misma de la guerra. Sería contrario a la naturaleza de ésta recibir golpes sin devolverlos. El ataque necesita de la defensa pues se desarrolla en el tiempo y en el espacio, y pierde progresivamente la superioridad que lo fundamenta. El ataque procura conquistar, no combatir; solo la defensa tiene por finalidad inmediata y absoluta la lucha. Entre el ataque y la defensa, una vez iniciadas las operaciones, hay necesariamente acción recíproca, cada cual quiere cumplir con su intención, positiva si se trata de conquistar y negativa si fuera el caso de conservar. Así, la defensa es la forma más fuerte de la guerra con fin negativo, mientras que el ataque se constituye en la forma más débil con fin positivo. La defensa sería la forma más fuerte y más segura con el propósito de quebrar la voluntad de lucha del enemigo.

La defensa, según nuestra concepción, no es otra cosa que la forma más fuerte de combate. La preservación de nuestras propias fuerzas y la destrucción de las del enemigo -en una palabra, la victoria- es el objetivo de este combate, pero al mismo tiempo no es su objetivo final. Ese objetivo es la preservación de nuestro propio estado político y la derrota del enemigo o, en una palabra, la paz que se tiene en mira, porque este conflicto sólo se soluciona con ella y termina en un resultado amplio (Clausewitz, 1983 [1832], p. 445).

La lucha se desarrolla entre dos Estados, o bien entre dos actores estratégicos (como ya explicamos), los cuales quieren imponer su voluntad al otro. Como cada Estado comprende un territorio y un ejército, estos elementos constituyen el blanco del ataque y la defensa. Cada cual quiere conservarse y destruir lo que posee el enemigo. Como el territorio está dominado por el ejército, pero no a la inversa, al menos a corto plazo, el primer objetivo de quien quiere abatir al otro está configurado por las fuerzas armadas del adversario.

\section{GUERRA Y PAZ}

Más allá de las maniobras defensivas y ofensivas se pueden colegir algunas reflexiones sustanciales. No era un concepto aceptado por la Europa de las contiendas dinásticas -empeñada en campañas militares a partir de intereses personales antes que de conjunto-, que la guerra, en cuanto hecho deliberado y consciente bajo responsabilidad del Estado nación, busca finalmente recuperar la paz y recomponer un escenario político adverso. El ad bellum con el cometido último de lograr la paz es una consideración clara dentro del tratado y su aporte a la política es sustantivo. No obstante, esto no fue cabalmente entendido por Roosevelt, Truman y Eisenhower durante la Segunda Guerra Mundial, ya que se enfocaron en la destrucción del poder militar del Eje como objetivo de la campaña, sin mayores previsiones respecto de las consecuencias potenciales. La guerra, explica Clausewitz y destaca Aron, se debe conducir con la idea de la paz final a lograr, no con la meta de la victoria operacional inmediata (Aron, 1987 [1976], p. 250).

Pero, ¿mantiene vigencia la condición beligerante de un actor estratégico en función de un territorio a preservar y un ejército que lo defienda? Con ciertas adaptaciones, la respuesta es afirmativa. Si asumimos que por ejército se interpreta un vector o brazo armado en capacidad de generar efectos militares, y por territorio 
a la localización geográfica desde o hacia donde se ejerce el poder con fines de conquista o preservación, podemos entonces deducir la vigencia del concepto clausewitziano. Se trataría de observar la conducta de ISIS, que proclamó el Califato Islámico con la intención de establecer su poder político (mediante el empleo del factor militar) a partir de un protoestado cuya capital fue Mosul. Vale decir, que un vector terrorista insurgente se propuso fines hegemónicos religiosos, para los cuales aplicó medios pertinentes (actor estratégico) y se apoderó de un territorio situado entre Irak y Siria.

Claro que la postura de Raymond Aron en torno de Clausewitz también tiene opositores. Entre ellos, uno de los más importantes es René Girard (2010), quien en su obra Clausewitz en los extremos apela a su teoría mimética para subrayar el fracaso de la política como ente rector y moderador de la violencia en la guerra. Girard hace foco en la obra de Aron y sostiene la tesis de que el propio Clausewitz advirtió la ingobernabilidad de las pasiones en el marco de la lucha, y que ante la falta de racionalidad que caracteriza la guerra se debe utilizar la política como instrumento de prudencia. Girard sostiene que ante semejante evidencia Clausewitz amañó un discurso en torno de la política, a sabiendas de lo estéril del recurso, pero con la esperanza de que al menos atemperase la violencia recíproca.

También varios autores relativizan la continuidad de los Estados nación como modelo de referencia en el concierto internacional. Como alternativa natural predicen la conformación de bloques, alianzas y comunidades que involucren varios países con intereses en común. Si bien ésta es una tendencia plausible, no es menos cierto que el planeta en su conjunto dista mucho de conformar un sistema armónico en el cual el conflicto fuera irrelevante. Por el momento el Estado nación continúa siendo la organización política en mejores condiciones de lidiar con el escenario de principios del tercer milenio, hasta para acompañar una posible transición hacia agrupamientos mayores.

Aun si todos los Estados invocaran la misma ideología, no se unirían bajo el reinado de uno solo, ni bajo la legislación de un parlamento planetario. Por un lapso que nadie puede precisar, la humanidad está condenada a la coexistencia más o menos pacífica entre pueblos que se comprenden mal, entre Estados que se quieren soberanos y entre ideologías incompatibles (Aron, 1987 [1976], p. 208).

Y a pesar de sus mejores esfuerzos, Aron nos advierte que el pseudoparlamentarismo de las Naciones Unidas caricaturiza los parlamentos nacionales, y la sociedad planetaria sigue siendo anárquica (Aron, 1987 [1976], p. 212). Si a esto le agregamos la aparición del terrorismo a escala, las diferencias religiosas y culturales, y las reacciones xenófobas, estaremos ante un rompecabezas de difícil ensamble.

\section{ConcLUSIONES}

Es preciso ahora elaborar algunas consideraciones. Para ello presentamos una serie de interrogantes:

¿La guerra es todavía una forma de acción de la política?

¿El factor militar como instrumento y medio de ejecución, se subordina a los fines impuestos por la política en el contexto de la guerra?

¿Se mantiene la condición de violencia para caracterizar los enfrentamientos bélicos?

¿Guarda aún sentido otorgarle a la política el rol de moderación para evitar el ascenso a los extremos de la violencia en la guerra?

¿Está vigente el significado político del aniquilamiento antes que la interpretación material del mismo?

¿Es aplicable actualmente la orientación y pertinencia del objetivo militar a lograr dentro del teatro de operaciones con el fin perseguido por la política en la guerra?

¿Se mantiene la diferenciación entre teoría y doctrina? ¿Es útil tal disquisición en la actualidad?

¿Reviste utilidad aplicar el concepto trinitario de la guerra a los conflictos armados de hoy?

¿Es eficaz el discurso clausewitziano para tratar las denominadas guerras hibridas y de cuarta generación? 
¿Continúa siendo atribución de la política determinar el tipo de guerra a emprender, fijar sus límites y establecer las condiciones finales de la paz?

¿Resulta todavía aplicable distinguir entre guerra real, guerra absoluta y guerra total?

¿Es pertinente tratar las nuevas amenazas a la seguridad en tanto formas de violencia que afectan la soberanía estatal desde el concepto amplio de la teoría clausewitziana?

¿Están en vigor las nociones de azar, fuerzas morales, fricción y genio militar para comprender las guerras de hoy?

¿Es plausible el Estado nación como organización política en los albores del siglo XXI?

La respuesta en todos los casos es afirmativa y demuestra no solo la trascendencia de Clausewitz, sino la utilidad del análisis agudo de Raymond Aron sobre su obra. Definitivamente, la vigencia de Aron tiene que ver con lo profundo de sus disquisiciones y la vinculación con otras ciencias y disciplinas, entre ellas, la polemología. Su aporte permite aproximarse a Clausewitz de manera más clara e inteligible, y, si bien su obra está situada en pleno siglo XX, trata aspectos intemporales de la guerra. Esto nos indica que tanto Clausewitz como Aron, cada uno en su tiempo y escenario, forman parte de las obras clásicas a las cuales recurrir para adentrarse en las esencias de lo bélico y del conflicto. Se podrá no coincidir con ellos, o hacerlo en forma relativa, pero en modo alguno se podrá obviarlos si se pretende entender un hecho que ha ocupado a la humanidad en forma constante en los últimos 5.500 años.

En síntesis, la guerra se mantiene como una opción de la política para dirimir los conflictos. Ha mutado a través del tiempo, acompañando los desarrollos tecnológicos, y se ha revestido de cambios instrumentales en sus sistemas de armas y formas tácticas y estratégicas, pero persevera en su naturaleza violenta, que la define y distingue.

"La guerra no es un pasatiempo, ni es una simple pasión por la osadía y el triunfo, ni el resultado de un entusiasmo sin trabas; es un medio serio para un fin serio" (Clausewitz, 1983 [1832], p. 23).

\section{REFERENCIAS BIBLIOGRÁFICAS}

Aron, R. (1987 [1976]). Pensar la guerra: Clausewitz. Buenos Aires: IPN.

Aron, R. (2009 [1987]). Sobre Clausewitz. Buenos Aires: Nueva Visión.

Clausewitz, C. (1983 [1832]). De la guerra. Buenos Aires: El Solar.

Clausewitz, C. (1999 [1832]). De la guerra. Madrid: Ministerio de Defensa.

Cornut, H. (2009). El discurso estratégico en el ámbito militar. Revista de la Escuela Superior de Guerra, 573, 62 - 77.

Der Goltz, C. (1927 [1883]). La nación en armas. Buenos Aires: Círculo Militar.

Fernández Vega, J. (1993). Carl von Clausewitz: Guerra, politica, filosofía. Buenos Aires: Almagesto.

Foucault, M. (1996). El orden del discurso. Madrid: La Piqueta.

Girard, R. (2010). Clausewitz en los extremos. Madrid: Katz.

Lidell Hart, B. (1960 [1941]). Estrategia: La aproximación indirecta. Buenos Aires: Círculo Militar.

Lidell Hart, B. (1969 [1934]). El espectro de Napoleón. Buenos Aires: Eudeba.

Ludendorff, E. (1964 [1935]). La guerra total. Buenos Aires: Pleamar.

Maquiavelo, N. (1994 [1531]). El principe. Barcelona: Fontana.

Maquiavelo, N. (2002 [1520]). Del arte de la guerra. Buenos Aires: Quadrata.

Morin, E. (2001). Introducción al pensamiento complejo. Barcelona: Gedisa.

OEA (2001). Cuestionario sobre nuevos enfoques de seguridad hemisférica. Recuperado de http://scm.oas.org/pdfs/20 02/cp09132.pdf

Schmitt, C. (2014 [1967]). Clausewitz como pensador politico o el honor de Prusia. Buenos Aires: Sieghels.

Van Creveld, M. (2007). La transformación de la guerra. Buenos Aires: s/e. 